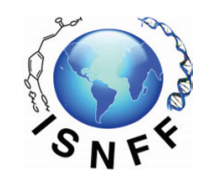

\title{
Effect of chitosan coatings incorporated with antioxidants of bamboo leaves and potassium sorbate on lipid oxidation and hydrolysis of scallop (Chlamys farreri) during refrigerated storage
}

\author{
Zi-Xuan Wua, Yu-Xin Liu ${ }^{\mathrm{a}, \mathrm{b}}$, Man-Man Yu ${ }^{\mathrm{a}}$, Fa-Wen Yinª, ${ }^{\mathrm{a}}$, Zi-Qiang Liu ${ }^{\mathrm{a}}$, Ao Lia \\ Da-Yong Zhou ${ }^{a, b^{*}}$, Bei-Wei Zhu ${ }^{\text {a,b* }}$ and Fereidoon Shahidic
}

\begin{abstract}
aSchool of Food Science and Technology, Dalian Polytechnic University, Dalian 116034, PR China
bNational Engineering Research Center of Seafood, Dalian 116034, PR China

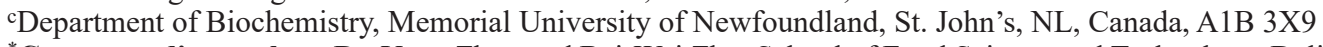

${ }^{*}$ Corresponding author: Da-Yong Zhou and Bei-Wei Zhu, School of Food Science and Technology, Dalian Polytechnic University, Dalian 116034, PR China. Tel: +86 0411 86323262; Fax: +860411 86323262; E-mail: zdyzf1@163.com and zhubeiwei@163.com

DOI: $10.31665 /$ JFB.2019.8208

Received: November 20, 2019; Revised received \& accepted: December 30, 2019

Citation: Wu, Z.-X., Liu, Y.-X., Yu, M.-M., Yin, F.-W., Liu, Z.-Q., Li, A., Zhou, D.-Y., Zhu, B.-W., and Shahidi, F. (2019). Effect of chitosan coatings incorporated with antioxidant of bamboo leaves and potassium sorbate on lipid oxidation and hydrolysis of scallop (Chlamys farreri) during refrigerated storage. J. Food Bioact. 8: 66-73.
\end{abstract}

\begin{abstract}
Nutrient loss, caused by lipid oxidation and hydrolysis, occurs in the scallop adductor muscle during refrigerated storage. To retard this process, chitosan coating with inclusion of antioxidant of bamboo leaves (AOB) and potassium sorbate (PS) were used. Results indicated the coatings employed could significantly inhibit the increases in total number of colonies, total volatile basic nitrogen, peroxide value, thiobarbituric acid-reactive substances, lipase activity and free fatty acid content as well as the decrease in contents of triacylglycerols, phosphatidylcholine, phosphatidylethanolamine and polyunsaturated fatty acids (PUFA) in the scallop adductor muscle during refrigerated storage. After 8 days, the contents of PUFA, eicosapentaenoic acid and docosahexenoic acid in the control adductor muscle decreased by $46.91,47.46$ and $45.50 \%$, respectively, while the corresponding values were $35.93-36.68,34.01-36.45$ and $32.73-37.50 \%$, respectively, for AOB- and PS-coated adductor muscles. Therefore, chitosan coatings incorporated with AOB and PS could retard nutrient loss by inhibiting lipid oxidation and hydrolysis.
\end{abstract}

Keywords: Shellfish; Chitosan coating; Refrigerated storage; Lipid oxidation; Lipid hydrolysis.

\section{Introduction}

Scallop is a commercially important bivalve with nearly 2.8 million tons production in 2017 (FAO, 2017). As a marine edible shellfish with increasing consumption, scallop has a unique and delicious flavor as well as healthy beneficial substances, such as proteins, carbohydrates, and lipids, especially long chain omega-3 polyunsaturated fatty acids (n-3 LC-PUFA) (Copeman and Parrish, 2005). High amounts of moisture, neutral $\mathrm{pH}$, active endogenous enzymes, and abundant nutrients like unsaturated fatty acids (UFA) and pro- teins make the scallop easily perishable (Ramón et al., 2008). Refrigerated storage is a common preservation method for maintaining and prolonging freshness of aquatic products (Chaijan et al., 2006; Jiménez Ruiz, 2012). However, refrigerated storage can not fully inhibit microbial growth and chemical reactions which cause quality deterioration of aquatic products (Aubourg et al., 1997).

In recent years, the method of coating preservation has been used to improve the quality stability of aquatic products during refrigeration (Jeon et al., 2002; Keshri and Sanyal, 2009). It is a relatively low-cost environmentally friendly technology with several advantages including lack of toxicity, biodegradability, biocom- 
patibility, and inhibition of microbial growth (Breda et al., 2017). The commonly used coating materials include cellulose, starch, chitosan, alginate, carrageenan, pectin, gelatin and wheat gluten, among which chitosan is most widely used due to its antifungal, antimicrobial and antioxidant properties (Dhall, 2013). Many research work has indicated that coating films incorporated with additives could effectively reduce microbes, total volatile basic nitrogen (TVB-N) and other indicators related to the decomposition of proteins in the refrigeration process of aquatic products, thus significantly improving the stability of products and quality retention (Fan et al., 2009; Jeon et al., 2002; Li et al., 2012; Keshri and Sanyal, 2009; Valipour et al., 2016; Pranoto et al., 2005).

Aquatic products contain a large amount of PUFA which makes them susceptible to oxidation (Selmi et al., 2010). Meanwhile, aquatic products are rich in endogenous enzymes such as lipases, which can hydrolyse lipids and then release free fatty acids (FFA) that are highly prone to oxidation (Aubourg et al., 1997). Previous studies have shown that coating films incorporated with additives such as tea polyphenols, $\alpha$-tocopherol and essential oils can inhibit lipid oxidation during refrigerated storage of aquatic products such as fish (Valipour et al., 2016; Li et al., 2012). Shellfish is rich in PUFA in the form of phospholipids (PL) as well as triacylglycerols (TAG) and lipases; thus its lipid components undergo oxidation and hydrolysis during refrigerated storage, resulting in reduced nutritional value of products (Cabot and Lumb, 1981; Selmi et al., 2010). However, to the best of our knowledge, research on the effects of chitosan coatings incorporated with additives on lipid oxidation and hydrolysis of shellfish during refrigerated storage has not yet been reported.

Thus, the aim of this study is to investigate the effect of chitosan coatings incorporated with additives on lipid oxidation and hydrolysis of shellfish during refrigerated storage. To fulfill this goal, scallop (Chlamys farreri) adductor muscle was coated with chitosan incorporated with antioxidant of bamboo leaves (AOB) and potassium sorbate (PS), respectively, and stored at $4{ }^{\circ} \mathrm{C}$. The proximate composition, total number of colonies, TVB-N, peroxide value (POV), thiobarbituric acid-reactive substances (TBARS), contents of TAG, phosphatidylcholine (PC), phosphatidylethanolamine (PE) as well as FFA, fatty acid composition and lipase activity of the samples during various storage periods were determined. The observations made in this study indicated the importance of the mechanism of lipid oxidation and hydrolysis of shellfish during refrigerated storage and provided means to ensure nutrition quality retention.

\section{Materials and methods}

\subsection{Materials}

Fresh scallops (Chlamys farreri) (average length of each scallop shell of 5-6.5 cm), harvested in the Yellow Sea, were purchased in April 2018 from a local market in Dalian, Liaoning, China. The samples were stored in polystyrene foam boxes with ice and immediately transported to the laboratory.

\subsection{Reagents and chemicals}

Chitosan, with $85 \%$ degree of deacetylation, was purchased from Sigma Co. (Saint Louis, MO, USA). AOB was purchased from Zhejiang Shengshi Biotechnology Co., Ltd. (Huzhou, Zhejiang, China). PS was purchased from Shanghai Xiangrui Biotechnology Co., LTD (Shanghai, China). High performance liquid chromatography (HPLC) grade methanol, n-hexane and isopropanol were purchased from Spectrum Chemical Mfg. Corp. (Gardena, CA, USA). All other reagents were of analytical grade and purchased from Damao Chemical Reagent Co. (Tianjin, China).

\subsection{Sample preparation}

Scallop adductor muscles were manually stripped from the shells and then chitosan coated according to the procedure reported by Valipour et al. (2016) with some modifications. After being washed, samples were randomly assigned into three batches and coated with three solutions: (1) $1.5 \%$ chitosan solution (w/v, control group); (2) $1.5 \%$ chitosan solution containing $0.2 \% \mathrm{AOB}(\mathrm{w} / \mathrm{v}$, AOB-coated group); (3) $1.5 \%$ chitosan solution containing $0.2 \%$ PS (w/v, PS-coated group). The coating solutions were prepared by dissolving chitosan in a $0.5 \%(\mathrm{v} / \mathrm{v})$ acetic acid solution to a final content of $1.5 \%(\mathrm{w} / \mathrm{v})$. For dissolving the chitosan completely, the solution was left for $1 \mathrm{~h}$ under agitation at $40^{\circ} \mathrm{C}$. Then different additives (AOB and PS) were introduced into the chitosan solutions, respectively, and the final coating solutions were homogenised at 10,000 rpm for $3 \mathrm{~min}$. For coating process, samples were immersed in each coating solution for $30 \mathrm{~min}$ and then well drained at room temperature. For each group, samples were individually wrapped and stored in a refrigerator at $4 \pm 1{ }^{\circ} \mathrm{C}$ for 8 days. All samples collections were performed every 4 days and then immediately stored at $-80{ }^{\circ} \mathrm{C}$ until use.

\subsection{Proximate composition analysis}

Ash and crude protein contents were determined according to the AOAC (1990) methods as 938.08 and 981.10, respectively. Total carbohydrates content was determined by the phenol-sulfuric acid method, using glucose as the standard (Dubois et al., 1956). Water content was determined according to the first method of Chinese standard GB 5009.3 (2016).

\subsection{Microbial assay}

Total numbers of colonies in the scallop adductor muscle were determined in plate count agar by the spread plate method (AOAC, 2002).

\subsection{Total volatile basic nitrogen (TVB-N) assay}

The TVB-N of the scallop adductor muscle was determined according to the second method of Chinese standard GB 5009.228 (2016).

\subsection{Peroxide value (POV) assay}

The POV of the scallop lipid was determined according to the first method of Chinese standard GB 5009.227 (2016). The POV was expressed as $\mathrm{mmol} / \mathrm{kg}$ reactive oxygen in lipid sample.

\subsection{Thiobarbituric acid-reactive substances (TBARS) assay}

The TBARS of the scallop adductor muscle were determined according to Khan et al. (2006) with some modifications (Xie et al., 2018) and expressed as mg malondialdehyde (MDA)/kg sample. 


\subsection{Lipid extraction}

A modified version of the Bligh and Dyer (1959) method was employed for total lipid extraction (Zhou et al., 2019). The extracted lipids were sealed under nitrogen and stored at $-80^{\circ} \mathrm{C}$ until further analysis within 2 weeks.

\subsection{Fatty acids composition analysis}

The determination of FA composition of the scallop lipid was achieved by using an Agilent 7890A GC-5975C MSD (Agilent, Palo Alto, CA, USA) equipped with an HP-5-MS capillary column $(30 \mathrm{~m} \times 0.25 \mathrm{~mm}, 0.25 \mu \mathrm{m})$ (Agilent). Preparation of fatty acid methyl esters of the sample was carried out according to a method previously described with slight modifications (Jeong and Lachance, 2001; Yin et al., 2015). One milligram of nonadecanoic acid (C19:0, Sigam-Aldrich, USA) was used as the internal standard for quantitative analysis of individual fatty acids and the results were expressed as $\mathrm{mg} / \mathrm{g}$ on a dry weight basis.

\subsection{Triacylglycerol (TAG) and free fatty acid (FFA) analysis}

The TAG and FFA were quantitatively determined according to our previous study (Xie et al., 2018), and the results were expressed as $\mathrm{mg} / \mathrm{g}$ (on a dry weight basis).

\subsection{Phosphotidylcholine (PC) and phosphotidylethanolamine (PE) analyses}

The PC and PE were quantitatively determined as described in a previous study (Zhou et al., 2019), results were expressed as $\mathrm{mg} / \mathrm{g}$ (on a dry weight basis).

\subsection{Lipase activity assay}

The determination of lipase activity in the scallop adductor muscle was performed using a kit according to the manufacturer's instructions (Jiancheng Technology Co., Nanjing, China), as described previously (Xie et al., 2018). One unit (U) of lipase activity is defined as $1 \mathrm{nmol}$ of released 4-methylumbelliferone per min at 37 ${ }^{\circ} \mathrm{C}$.

\subsection{Statistical analysis}

Each experiment was relicated three times. The statistical analyses were performed by Duncan test using SPSS version 16.0 (SPSS Inc., Chicago, IL, USA). $P$ values of $<0.05$ were considered statistically significant.

\section{Results and discussion}

\subsection{Changes in proximate composition of scallop adductor muscle during refrigerated storage}

The fresh scallop adductor muscles with different treatments contained $3.84-3.92 \%$ lipid, $79.87-80.79 \%$ protein, $17.10-17.58 \%$ total carbohydrates and $4.48-4.69 \%$ ash (on a dry weight basis) before refrigerated storage. During the 8 days of refrigerated storage, the protein contents of the scallop adductor muscles decreased slightly, while the ash contents increased marginally, but the corresponding values for other components remained unchanged (Figure 1). Arannilewa et al. (2006) also reported a decreasing trend of protein content and a slightly rising trend in the ash content of tilapia fish (Sarotherodun galiaenus) during the frozen storage. This may be attributed to the action of endogenous enzymes and bacteria which cause the decomposition of proteins in food during storage (Arannilewa et al., 2006).

\subsection{Changes in total numbers of colonies of scallop adductor muscle during refrigerated storage}

The total numbers of colonies in the scallop adductor muscles with all treatmentsincreased time-dependently during refrigerated storage (Figure 2a). The initial values of colonies of the control, AOBcoated and PS-coated adductor muscles were $3.26 \pm 0.17,3.24 \pm$ 0.15 and $3.22 \pm 0.22 \lg (\mathrm{CFU} / \mathrm{g})$, respectively, which increased to $6.72 \pm 0.10,5.22 \pm 0.17$ and $5.14 \pm 0.32 \lg (\mathrm{CFU} / \mathrm{g})$, respectively, after 8 days of refrigerated storage, and increased by 2.06-, 1.61and 1.60-fold, respectively. By contrast, the AOB- and PS-coated adductor muscles both showed significantly lower values of colonies than that of the control adductor muscle during the refrigerated storage $(P<0.05)$.

The microbial spoilage of aquatic products is one of the important reasons for the large amount of food waste during storage (Chaillou et al., 2015). Therefore, inhibition of the growth of bacterial communities is a crucial means to retard the spoilage of aquatic products during storage. Previous studies have also indicated that chitosan coatings incorporated with polyphenols and preservatives could significantly inhibit the growth of bacterial population and retard food spoilage (Valipour et al., 2016; Li et al., 2012; Pranoto et al., 2005). For example, Li et al. (2012) reported that large yellow croaker (Pseudosciaena crocea) coated with chitosan incorporated with tea polyphenol had significantly lower microorganisms counts than control group during refrigerated storage. Pranoto et al. (2005) reported that chitosan coating incorporated with PS increased the resistance of several kinds of food pathogen bacteria. PS is a common antibacterial preservative used by the food industry. The polyphenols have been proven to possess antibacterial activity by affecting the osmotic pressure to alter the cell morphology, thereby destroying the plasma membrane and causing the leakage of cellular components (Perumalla and Hettiarachchy, 2011). Due to the migration of the additives from coating materials to the surface of the products (Sangsuwan et al., 2015), the additives could interact with the bacteria in the adductor muscle during refrigerated storage to achieve their antibacterial activity.

\subsection{Changes in total volatile basic nitrogen (TVB-N) of scallop adductor muscle during refrigerated storage}

The values of TVB-N of the scallop adductor muscles with different treatments all increased gradually during the course of refrigerated (Figure 2b). The initial values of TVB-N of the control, AOB-coated and PS-coated adductor muscles were $10.38 \pm 0.20$, $11.03 \pm 0.26$ and $12.28 \pm 0.13 \mathrm{mg} / 100 \mathrm{~g}$, respectively, which increased to $22.30 \pm 0.26,19.37 \pm 0.19$ and $20.71 \pm 0.20 \mathrm{mg} / 100 \mathrm{~g}$, respectively, after 8 days of refrigerated storage, and increased by 2.15-, 1.76- and 1.69-fold, respectively. By contrast, the AOB- and PS-coated adductor muscles both had significantly lower values of 

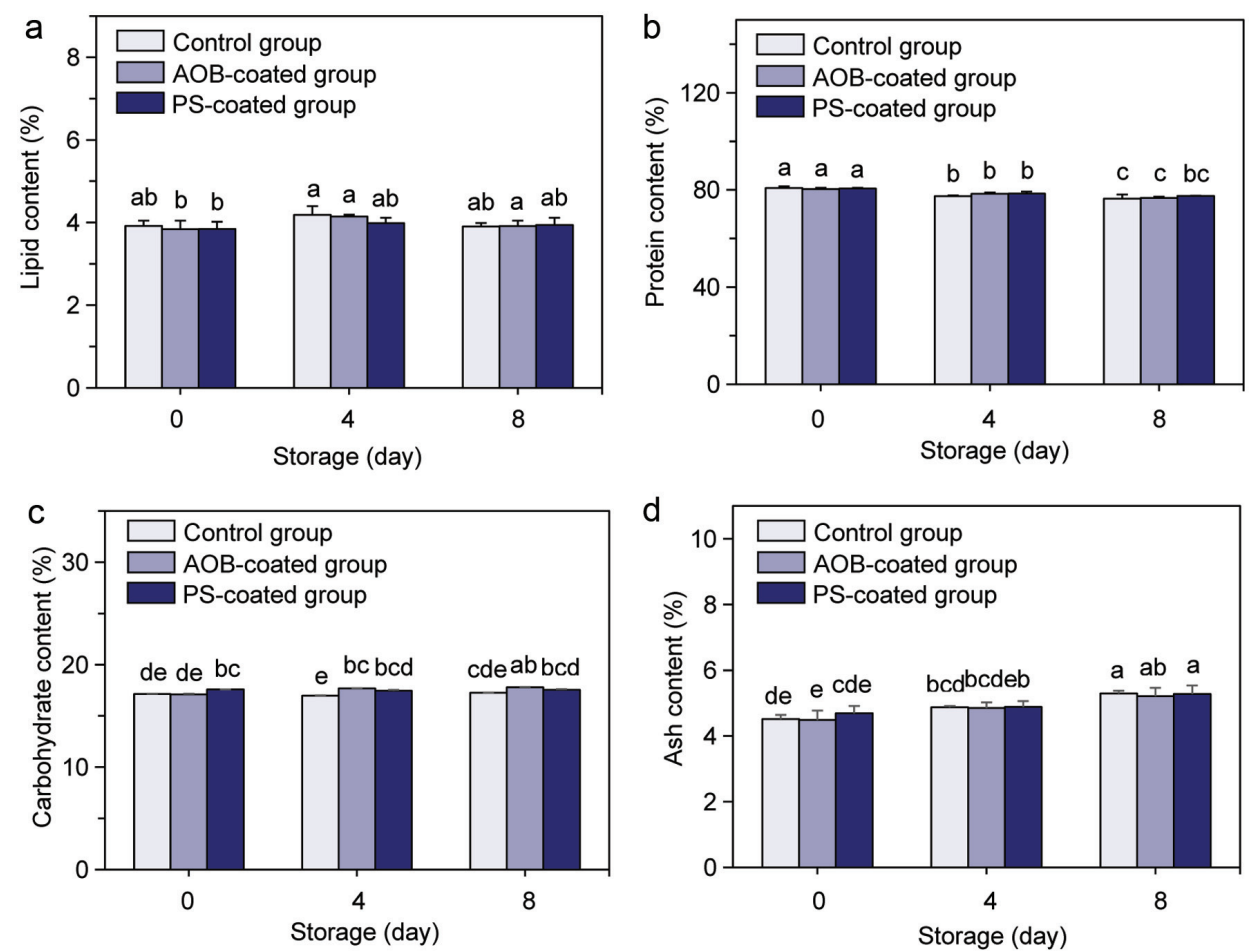

Figure 1. Changes in lipid (a), protein (b), carbohydrate (c) and ash (d) contents of the control scallop adductor muscle, AOB-coated scallop adductor muscle and PS-coated scallop adductor muscle during refrigerated storage. Values in the different column with different lowercase letters (a-e) are significantly different at $P<0.05$.

TVB-N than that of the control adductor muscle during refrigerated storage $(P<0.05)$.

Total volatile basic nitrogen are alkaline nitrogenous substances such as ammonia and amines produced by the decomposition of amino acids during the process of food spoilage under the action of enzymes and bacteria (Jiménez Ruiz et al., 2012). Therefore, TVB-N is widely used as an indicator to represent the stage of deterioration or loss of freshness of aquatic products (Jiménez Ruiz et al., 2012). Previous studies have also indicated that edible coatings incorporated with polyphenols and preservatives could significantly inhibit the increase of TVB-N in food stuffs during storage (Jeon et al., 2002; Li et al., 2012; Keshri and San- yal, 2009). For example, Li et al. (2012) reported that chitosan coating incorporated with tea polyphenol could more effectively maintain the TVB-N values of large yellow croaker (Pseudosciaena crocea). In addition, Keshri and Sanyal (2009) reported that alginate coatings incorporated with preservatives (sodium ascorbate, citric acid and glycerol) significantly retarded the increase of TVB-N in meat patties. Spoilage bacteria and endogenous enzymes in food stuffs play important roles in increasing TVB-N (Fan et al., 2009). Therefore, the inhibitory effects of the two types of chitosan coatings on TVB-N of the scallop adductor muscle during refrigerated storage may be attributed to their antibacterial activities.
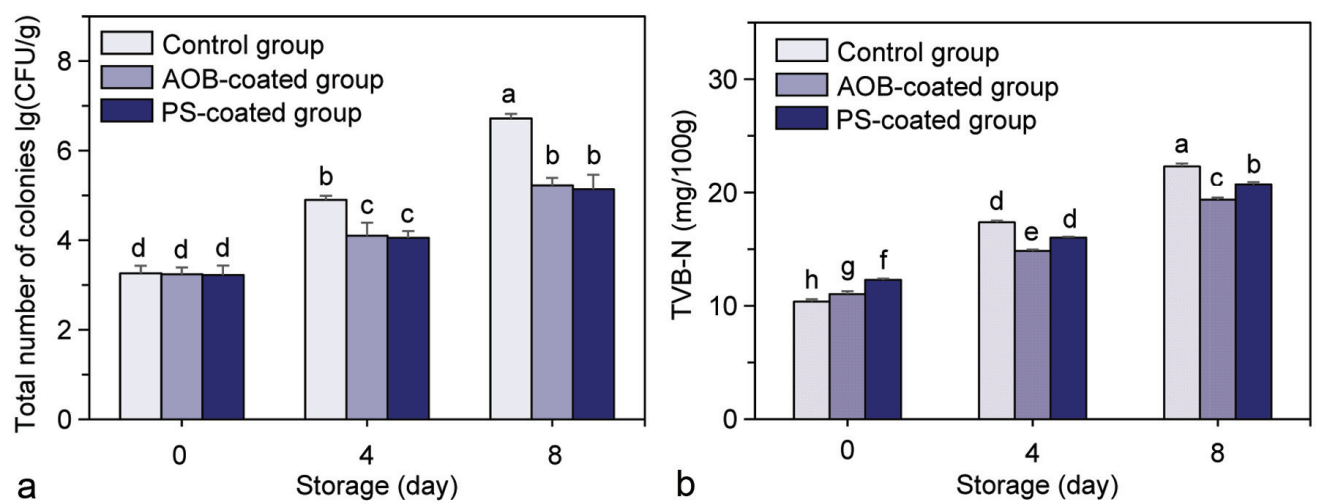

Figure 2. Changes in total numbers of colonies (a) and TVB-N (b) of the control scallop adductor muscle, AOB-coated scallop adductor muscle and PScoated scallop adductor muscle during refrigerated storage. Values of different groups with different lowercase letters (a-h) are significantly different at $P<0.05$. 

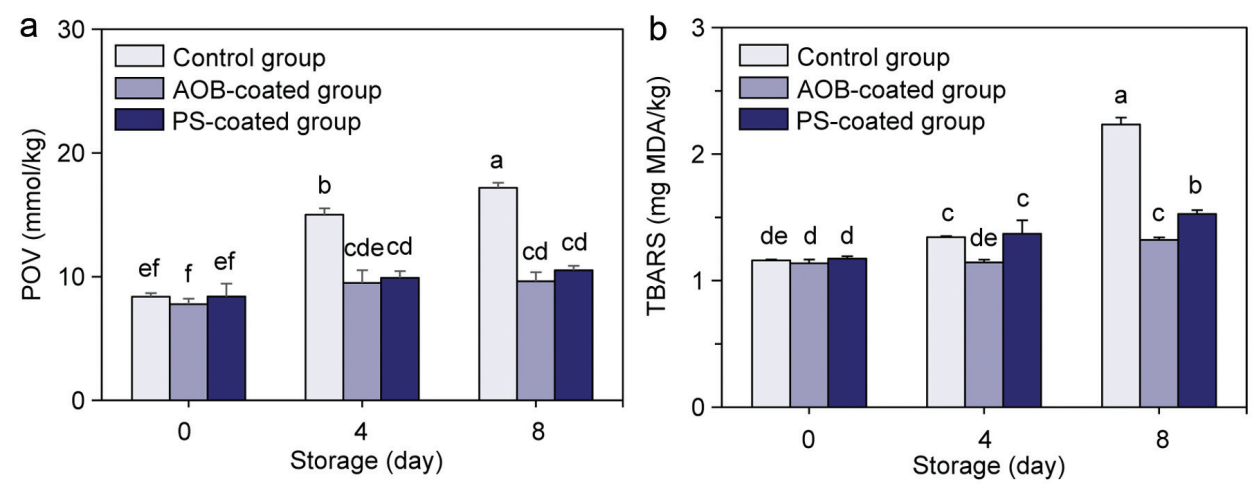

Figure 3. Changes in POV (a) and TBARS (b) of the control scallop adductor muscle, AOB-coated scallop adductor muscle and PS-coated scallop adductor muscle during refrigerated storage. Values of different groups with different lowercase letters (a-f) are significantly different at $P<0.05$.

\subsection{Changes in lipid oxidation levels of scallop adductor muscle during refrigerated storage}

The indicators of lipid oxidation, including POV (Figure 3a) and TBARS (Figure 3b), of the scallop adductor muscles with different treatments all increased time-dependently during refrigerated storage. The initial POV of lipids from the control, AOB-coated and PS-coated adductor muscles were $8.38 \pm 0.29,7.77 \pm 0.44$ and $8.39 \pm 1.05 \mathrm{mmol} / \mathrm{kg}$, respectively, which increased to $17.18 \pm 0.41$, $9.63 \pm 0.73$ and $10.52 \pm 0.35 \mathrm{mmol} / \mathrm{kg}$, respectively, after 8 days of refrigerated storage, and increased by 2.05-, 1.24- and 1.25-fold, respectively. Meanwhile, the initial values of TBARS for the three aforementioned adductor muscles were $1.16 \pm 0.01,1.14 \pm 0.03$ and $1.17 \pm 0.02 \mathrm{mg} \mathrm{MDA} / \mathrm{kg}$, respectively, which increased to $2.23 \pm$ $0.05,1.32 \pm 0.02$ and $1.53 \pm 0.03 \mathrm{mg} \mathrm{MDA} / \mathrm{kg}$, respectively, after 8 days of refrigerated storage, and increased by 1.92-, 1.16- and 1.31fold, respectively. Obviously, chitosan coatings incorporated with AOB and PS significantly reduced the increase of POV and TBARS in the adductor muscles during refrigerated storage.

The fresh adductor muscles before refrigerated storage contained 7.55-7.61 mg/g PUFAs, $1.34-1.35 \mathrm{mg} / \mathrm{g}$ monounsaturated fatty acids (MUFA) and 4.08-4.10 mg/g saturated fatty acids (SFA) (dry basis) (Table 1). Among PUFA, eicosapentaenoic acid (EPA, C20:5 n-3, 2.94-2.99 mg/g) and docosahexaenoic acid (DHA, $\mathrm{C} 22: 6 \mathrm{n}-3,3.87-3.92 \mathrm{mg} / \mathrm{g}$ ) were dominant. After refrigerated storage, the contents of MUFA, PUFA, EPA and DHA in all scallop adductor muscles were significantly reduced. For the control adductor muscle, those lipid components decreased by 41.79, 46.91, 47.46 and $45.50 \%$, respectively. While the corresponding values were $32.09,35.93,36.45$ and $32.73 \%$, respectively, for the AOBcoated adductor muscle, and were $36.30,36.68,34.01,37.50 \%$, respectively, for the PS-coated adductor muscle. By contrast, chitosan coatings incorporated with AOB and PS could significantly prevent the oxidation of PUFA, especially EPA and DHA, in the adductor muscles during refrigerated storage.

Lipid oxidation is a major cause for quality deterioration of aquatic products during refrigerated storage (Jeon et al., 2002). The mechanism of lipid oxidation occurring in refrigerated aquatic products is mainly autoxidation (Sun et al., 2011). The UFA molecules generate lipid alkyl radicals by losing a hydrogen atom and then form peroxyl radical by reacting quickly with oxygen. While peroxyl radical can form hydroperoxide and another lipid alkyl free radical by abstracting another hydrogen from an unsaturated lipid, and then propagate the free radical chain reaction (Johnson and Decker, 2015; Nawar, 1996). In this process, the primary oxi- dation products (hydroperoxides) are unstable and can be easily decomposed into various secondary oxidation products such as aldehydes, alcohols, ketones, hydrocarbons, volatile organic acids, and epoxy compounds (Kindleysides et al., 2012). In this study, the increase of primary oxidation products (POV) and secondary oxidation products (TBARS), as well as the decrease of PUFA in the adductor muscles during refrigerated storage were significantly inhibited by chitosan coatings incorporated with AOB and PS, indicating the antioxidant effects of the coatings.

Previous studies have also indicated that chitosan coatings incorporated with polyphenols could significantly inhibit lipid oxidation (Valipour et al., 2016; Li et al., 2012). For example, Li et al. (2012) reported that large yellow croaker (Pseudosciaena crocea) coated with chitosan incorporated with tea polyphenols had significantly lower values of POV and TBARS during cold storage. AOB used in this study was a commercial polyphenolic antioxidant which is listed in the Chinese standard GB 2760 (2014). Its antioxidant activity is provided by supplying hydroxyl hydrogen to lipid peroxyl radicals and could also act as inhibitor of lipid oxidation by removing singlet oxygen molecules (Brewer, 2011). PS has also been proven to possess antioxidant activity by influencing the electroreduction of oxygen as well as its interaction with reactive oxygen species (Korotkova et al., 2006). Therefore, the inhibitory effects of the two types of chitosan coatings on lipid oxidation in scallop adductor muscle during refrigerated storage may be due to their antioxidant activities.

\subsection{Changes in lipid hydrolysis degrees of scallop adductor muscle during refrigerated storage}

During refrigerated storage, the contents of TAG (Figure 4a), PC (Figure 4c) and PE (Figure 4d) decreased time-dependently, while the content of FFA (Figure 4b) increased time-dependently. The initial values for the four aforementioned lipid components in the adductor muscles before refrigerated storage were 10.56-11.34, 6.45$6.48,2.14-2.18$ and $6.20-6.38 \mathrm{mg} / \mathrm{g}$ (dry basis), respectively. After 8 days of refrigerated storage, the contents of TAG, PC and PE in the control adductor muscle decreased by $19.89,19.14$ and $19.14 \%$, respectively, and the content of FFA increased by 1.63 -fold. At the same time, the corresponding values for the AOB-coated adductor muscle were $8.05,14.06,14.06 \%$ and 1.21 -fold, respectively, while those values for the PS-coated adductor muscle were 9.05, 15.81, $15.81 \%$ and 1.19 -fold, respectively. By contrast, chitosan coatings incorporated with AOB and PS significantly reduced the decline of TAG, PC and PE and the enhancement of FFA in the adductor mus- 


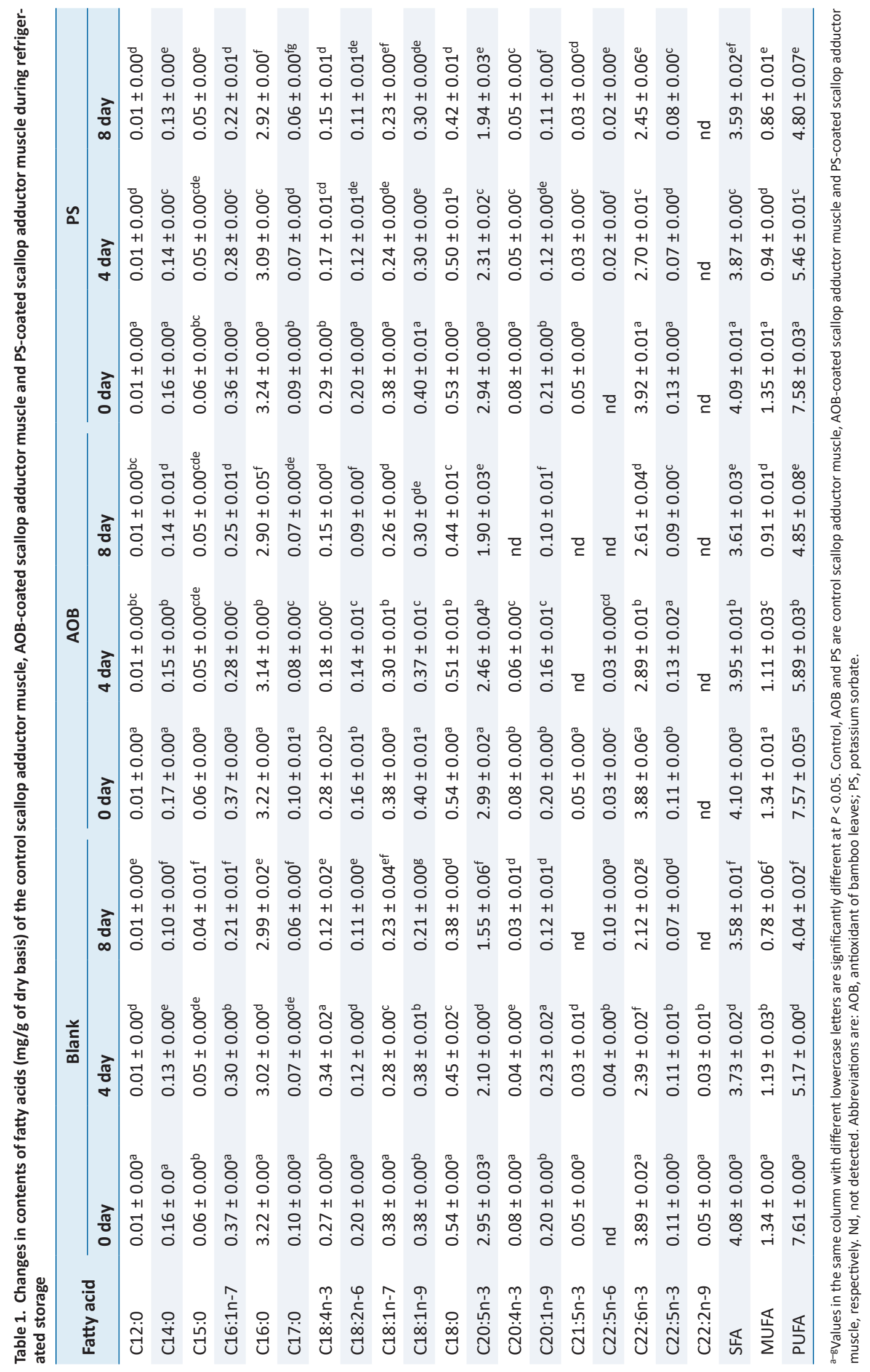



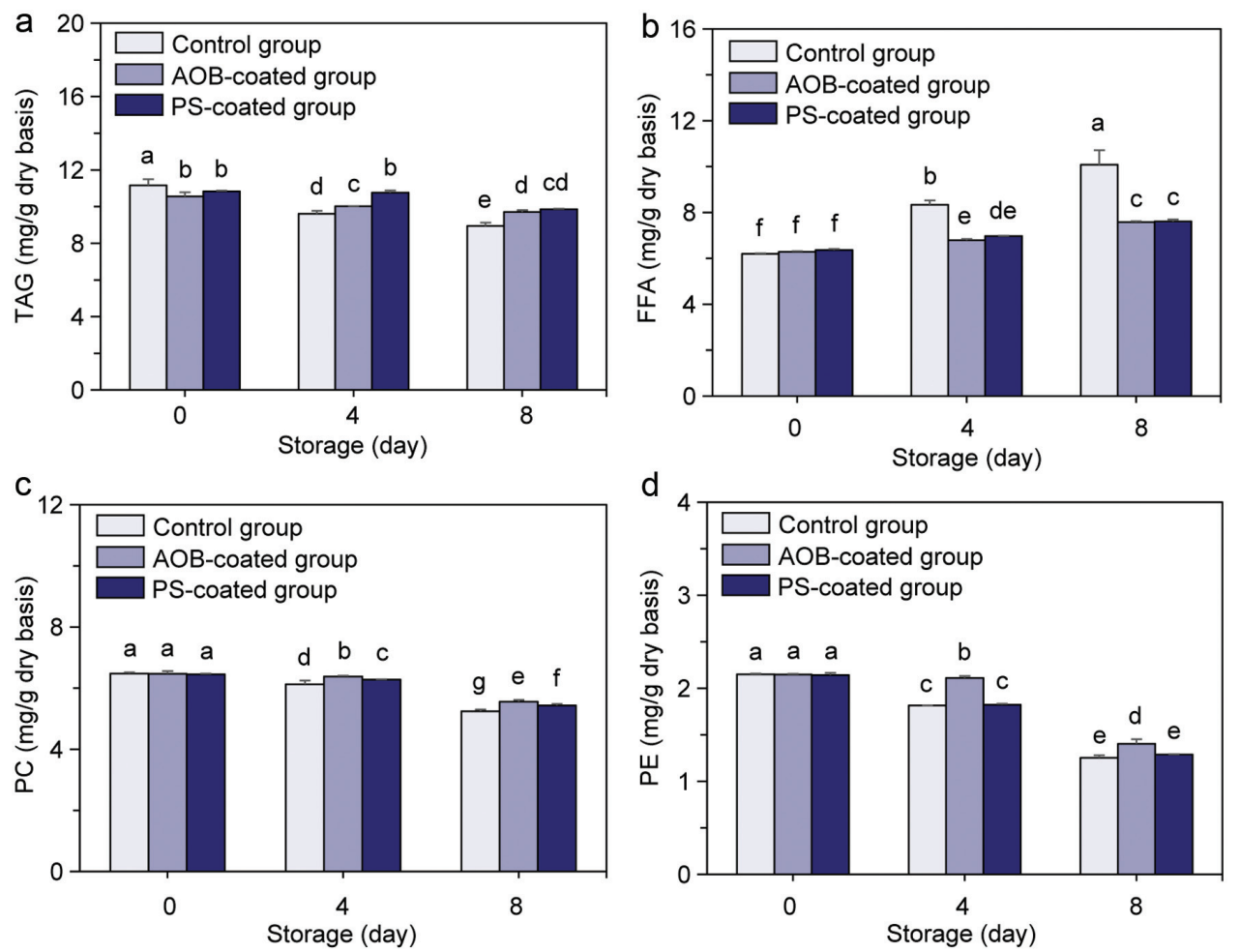

Figure 4. Changes in contents of TAG (a), FFA (b), PC (c) and PE (d) in the control scallop adductor muscle, AOB-coated scallop adductor muscle and PScoated scallop adductor muscle during refrigerated storage. Values of different groups with different lowercase letters (a-g) are significantly different at $P$ $<0.05$.

cles during refrigerated storage. Meanwhile, the activities of lipase in the adductor muscles all increased gradually along with the storage time (Figure 5). The initial lipase activities of the control adductor muscle, AOB-coated adductor muscle and PS-coated adductor muscle before refrigerated storage were $129.3 \pm 5.17,121.54$ \pm 5.17 and $102.58 \pm 9.08 \mathrm{U} / \mathrm{g}$, respectively, and the corresponding values rose to $359.46 \pm 14.40,258.60 \pm 7.76$ and $205.16 \pm 18.16$ $\mathrm{U} / \mathrm{g}$, respectively, after 8 days of refrigerated storage, and increased by 2.78-, 2.13- and 2.00-fold, respectively.

The decrease of TAG, PC and PE contents and the increase of

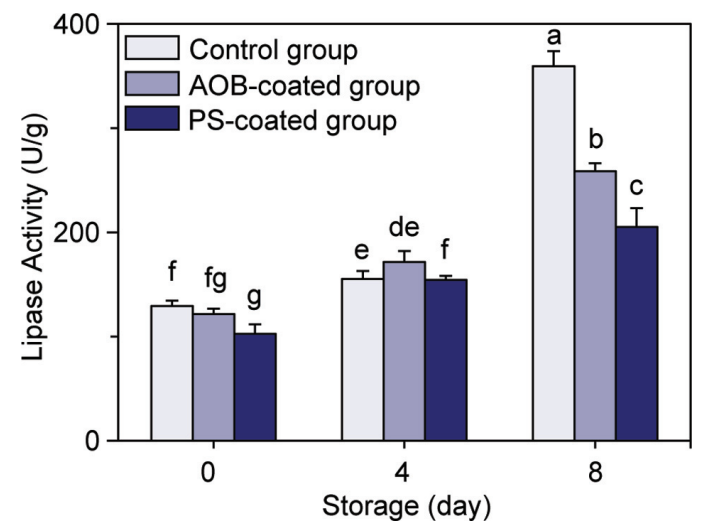

Figure 5. Changes in lipase activity of the control scallop adductor muscle, AOB-coated scallop adductor muscle and PS-coated scallop adductor muscle during refrigerated storage. Values of different groups with different lowercase letters $(\mathrm{a}-\mathrm{g})$ are significantly different at $P<0.05$.
FFA content in the adductor muscles indicated the occurrence of lipid hydrolysis during refrigerated storage. A previous study also reported the decrease in the contents of TAG and PL as well as an increase in the content of FFA in sardine (Sardinella gibbosa) muscle during iced storage due to the hydrolysis of lipids (Chaijan et al., 2006). The presence of lipase in adductor muscle and the increase of its activity during refrigerated storage suggested that the enzyme could conduce to the hydrolysis of lipids. Cabot and Lumb (1981) also proposed the important role of lipase in TAG hydrolysis at low temperatures. Our results indicated that chitosan coatings incorporated with AOB and PS inhibited the growth of lipase activity, thereby inhibiting lipid hydrolysis. The lipase of aquatic products includes both endogenous enzymes and exogenous enzymes produced by spoilage organisms such as Bacillus, Pseudomonas and Burkholderia (Gupta et al., 2004). In this study, chitosan coatings incorporated with AOB and PS significantly inhibit bacterial proliferation, which may be the reason for the reduction of lipase activity and the consequent inhibition of lipid hydrolysis.

\section{Conclusion}

Nutrient loss, caused by lipid oxidation and hydrolysis, occurs in the adductor muscle of scallop during refrigerated storage. Our results indicated that chitosan coatings incorporated with $\mathrm{AOB}$ and PS could significantly inhibit the increases in POV, TBARS, and FFA contents as well as the decreases in contents of TAG, PC, PE and PUFA especially EPA and DHA in the scallop adductor muscle during refrigerated storage. Thus, chitosan coatings with added components could retard nutrient loss by inhibiting lipid oxidation and hydrolysis. 


\section{Acknowledgments}

This work was financially supported by "National Key R\&D Program of China (2018YFD0901000)", "National Natural Science Foundation of China (31871759; U1808203)", "Project of Distinguished Professor of Liaoning Province, China (2015-153)", and "Dalian Science and Technology Innovation Fund Project (2019J11CY005)".

\section{Conflict of interest}

The authors declare that they have no conflict of interest.

\section{References}

AOAC. (1990). Official methods of analysis of the Association of Official Analytical Chemists. Association of Official Analytical Chemists, Washington, DC, 15th edn.

AOAC. (2002). Official methods of analysis of the Association of Official Analytical Chemists. Association of Official Analytical Chemists, Washington, DC, 16th edn.

Arannilewa, S.T., Salawu, S.O., Sorungbe, A.A., and Olasalawu, B.B. (2006). Effect of frozen period on the chemical, microbiological and sensory quality of frozen tilapia fish (sarotherodun galiaenus). Nutr. Health 18(2): 185.

Aubourg, S., Gallardo, J.M., and Medina, I. (1997). Changes in lipids during different sterilizing conditions in canning albacore (Thunnus alalunga) in oil. Int. J. Food Sci. Technol. 32: 427-431.

Bligh, E.G., and Dyer, W.J. (1959). A rapid method of total lipid extraction and purification. Can. J. Biochem. Physiol. 37: 911-917.

Breda, C.A., Morgado, D.L., de Assis, O.B.G., and Duarte, M.C.T. (2017) Effect of chitosan coating enriched with pequi (Caryocar brasiliense Camb.) peel extract on quality and safety of tomatoes (Lycopersicon esculentum Mill.) during storage. J. Food Process. Preserv. 41(6): e13268.

Brewer, M.S. (2011). Natural antioxidants: Sources, compounds, mechanisms of action, and potential applications. Compr. Rev. Food Sci. F. 10(4): 221-247.

Cabot, M.C., and Lumb, R.H. (1981). The activity of a low temperature lipase in the larvae of sarcophaga bullata, (diptera:sarcophagidae). Comp. Biochem. Physiol. B 68: 325-328.

Chaijan, M., Benjakul, S., Visessanguan, W., and Faustman, C. (2006). Changes of lipids in sardine (Sardinella gibbosa) muscle during iced storage. Food Chem. 99: 83-91.

Chaillou, S., Chaulot-Talmon, A., Caekebeke, H., Cardinal, M., Christieans, S., Denis, C., Desmonts, M.H., Dousset, X., Feurer, C., Hamon, E., Joffraud, J., La Carbona, S., Leroi, F., Leroy, S., Lorre, S., Macé, S., Pilet, M., Prévost, H., Rivollier, M., Roux, D., Talon, R., Zagorec, M., and Champomier-Vergès, M. (2015). Origin and ecological selection of core and food-specific bacterial communities associated with meat and seafood spoilage. ISME J. 9(5): 1105-1118.

Chinese Standard GB 2760. (2014). Using standard of food additive. China Standards Press of China, Beijing.

Chinese Standard GB 5009.227. (2016). Determination of peroxide value in food. China Standards Press of China, Beijing.

Chinese Standard GB 5009.228. (2016). Determination of volatile base nitrogen in food. China Standards Press of China, Beijing.

Chinese Standard GB 5009.3. (2016). Determination of moisture in food. China Standards Press of China, Beijing.

Copeman, L.A., and Parrish, C.C. (2005). Lipid classes, fatty acids, and sterols in seafood from Gilbert Bay, southern Labrador. J. Agric. Food Chem. 53(7): 2778-2778.

Dhall, R.K. (2013). Advances in edible coatings for fresh fruits and vegetables: A review. Crit. Rev. Food Sci. Nutr. 53: 435-450.

Dubois, M., Gilles, K.A., Hamilton, J.K., Rebers, P.T., and Smith, F. (1956). Colorimetric method for determination of sugars and related sub- stances. Anal. Chem. 28(3): 350-356.

Fan, W., Sun, J., Chen, Y., Qiu, J., Zhang, Y., and Chi, Y. (2009). Effects of chitosan coating on quality and shelf life of silver carp during frozen storage. Food Chem. 115(1): 66-70.

FAO. FIGIS list of species for fishery global production statistics. URL http:// www.fao.org/fishery/statistics/en.

Gupta, R., Gupta, N., and Rathi, P. (2004). Bacterial lipases: an overview of production, purification and biochemical properties. Appl. Microbiol. Biotechnol. 64(6): 763-781.

Jeon, Y.J., Kamil, J.Y.V.A., and Shahidi, F. (2002). Chitosan as an edible invisible film for quality preservation ofherring and atlantic cod. J. Agric Food Chem. 50(18): 5167-5178.

Jeong, W.S., and Lachance, P.A. (2001). Phytosterols and fatty acids in fig (Ficus carica, var. Mission) fruit and tree components. J. Food Sci. 66: 278-281.

Jiménez Ruiz, E.I., Ocaño Higuera, V.M., Maeda Martínez, A.N., Castillo Yáñez, F.J., Varela Romero, A., Graciano Verdugo, A.Z., and Márquez Ríos, E. (2012). Quality and shelf life of the adductor muscle of lions paw scallop Nodipecten subnodosus transported and stored whole in refrigeration. Interciencia 37(6): 464-469.

Johnson, D.R., and Decker, E.A. (2015). The role of oxygen in lipid oxidation reactions: a review. Annu. Rev. Food Sci. Technol. 6(1): 171-190.

Keshri, R.C., and Sanyal, M.K. (2009). Effect of sodium alginate coating with preservatives on the quality of meat patties during refrigerated $\left(4 \pm 1^{\circ} \mathrm{C}\right)$ storage. J. Muscle Foods 20(3): 275-292.

Kindleysides, S., Quek, S.Y., and Miller, M.R. (2012). Inhibition of fish oil oxidation and the radical scavenging activity of New Zealand seaweed extracts. Food Chem. 133(4): 1624-1631.

Korotkova, E.I., Avramchik, O.A., Angelov, T.M., and Karbainov, Y.A. (2006). Investigation of antioxidant activity and lipophilicity parameters of some preservatives. Electrochim. Acta 51(2): 324-332.

Li, T., Hu, W., Li, J., Zhang, X., Zhu, J., and Li, X. (2012). Coating effects of tea polyphenol and rosemary extract combined with chitosan on the storage quality of large yellow croaker (pseudosciaena crocea). Food Control 25(1): 101-106.

Nawar, W.W. (1996). Lipids in food chemistry. Marcel Dekker Inc, New York (USA), pp. 225-319.

Perumalla, A.V.S., and Hettiarachchy, N.S. (2011). Green tea and grape seed extracts- potential applications in food safety and quality. Food Res. Int. 44(4): 827-839.

Pranoto, Y., Rakshit, S.K., and Salokhe, V.M. (2005). Enhancing antimicrobial activity of chitosan films by incorporating garlic oil, potassium sorbate and nisin. LWT - Food Sci. Technol. 38(8): 859-865.

Ramón, P.A., Enrique, M.R., María, E.L., Guillermina, G., Alfonso, N.M., and Víctor, M.O. (2008). Postmortem changes in the adductor muscle of pacific lions-paw scallop (nodipecten subnodosus) during ice storage. Food Chem. 106(1): 253-259.

Sangsuwan, J., Rattanapanone, N., and Pongsirikul, I. (2015). Development of active chitosan films incorporating potassium sorbate or vanillin to extend the shelf life of butter cake. Int. J. Food Sci. Technol. 50(2): 323-330.

Selmi, S., Bouriga, N., Cherif, M., Toujani, M., and Trabelsi, M. (2010). Effects of drying process on biochemical and microbiological quality of silverside (fish) Atherina lagunae. Int. J. Food Sci. Technol. 45: $1161-1168$.

Sun, Y.E., Wang, W.D., Chen, H.W., and Li, C. (2011). Autoxidation of unsaturated lipids in food emulsion. Crit. Rev. Food Sci. Nutr. 51: 453-66.

Valipour Kootenaie, F., Ariaii, P., Khademi Shurmasti, D., and Nemati, M. (2017). Effect of chitosan edible coating enriched with eucalyptus essential oil and $\alpha$-tocopherol on silver carp fillets quality during refrigerated storage. J. Food Safety 37(1): e12295.

Xie, H.K., Zhou, D.Y., Hu, X.P., Liu, Z.Y., Song, L., and Zhu, B.W. (2018) Changes in lipid profiles of dried clams (Mactra chinensis Philippi and Ruditapes philippinarum) during accelerated storage and prediction of shelf life. J. Agric. Food Chem. 66: 7764-7774.

Yin, F.W., Liu, X.Y., Fan, X.R., Zhou, D.Y., Xu, W.S., Zhu, B.W., and Murata, Y.Y. (2015). Extrusion of Antarctic krill (Euphausia superba) meal and its effect on oil extraction. Int. J. Food Sci. Technol. 50: 633-639.

Zhou, X., Zhou, D.Y., Liu, Z.Y., Yin, F.W., Liu, Z.Q., Li, D.Y., and Shahidi, F. (2019). Hydrolysis and oxidation of lipids in mussel Mytilus edulis during cold storage. Food Chem. 272: 109-116. 